\title{
Discussion: Seismic performance of lightly reinforced structural walls for design purposes
}

\section{Ari Wibowo}

Research Fellow, Faculty of Engineering and Industrial Sciences,

Swinburne University of Technology, Hawthorn, Australia

\section{John L. Wilson}

Professor, Faculty of Engineering and Industrial Sciences, Swinburne University of Technology, Hawthorn, Australia

\section{Nelson T. K. Lam}

Associate Professor, Department of Infrastructure Engineering, University of Melbourne, Parkville, Australia

\section{Emad F. Gad}

Professor, Faculty of Engineering and Industrial Sciences, Swinburne University of Technology, Hawthorn, Australia

\section{Yiqiu Lu}

PhD Candidate, Department of Civil and Environmental Engineering, University of Auckland, Auckland, New Zealand

\section{Richard S. Henry}

Lecturer, Department of Civil and Environmental Engineering, University of Auckland, Auckland, New Zealand

\section{Contribution by Yiqiu Lu and Richard S. Henry}

The paper on the seismic performance of lightly reinforced concrete walls by Wibowo et al. (2013) is both interesting and timely, but several points require clarification.

The authors defined lightly reinforced structural walls as having a total vertical reinforcement ratio between $0 \cdot 2 \%$ and $2 \%$. However, the lateral load behaviour of concrete walls within this range would vary substantially. A single flexural crack may form in a wall with $0 \cdot 2 \%$ vertical reinforcement, whereas a wall with $2 \%$ vertical reinforcement would be expected to form a ductile plastic hinge with a large number of well-distributed cracks. The range of vertical reinforcement ratios may be too large to develop a suitable analytical model to represent the range of expected behaviour.

The typology of walls included in the literature review is not well defined and this may explain the large scatter of results that can be observed in Figure 1. For example, the walls tested by Gebreyohaness et al. were intended to represent walls in a building constructed in 1936 that were identified as having several deficiencies including the use of plain vertical reinforcement and inadequate splices (Gebreyohaness et al., 2011) The experimental results of Gebreyohaness' walls cannot be compared against walls with ductile detailing that satisfy modern design standards. Additionally, walls WPS5, WPS7 and WPS8 were reported as having an ultimate drift capacity of $3 \cdot 5 \%$. The strength of these walls at $3.5 \%$ drift had degraded significantly to less than $50 \%$ of the maximum strength, with either the splice or vertical reinforcement having failed at lower drifts. The ultimate drift is often defined as occurring when the strength drops below $80 \%$ of the maximum strength (Park, 1989) and the definition of ultimate drift should be clarified.

In Table 3, the aspect ratios of the walls would be better represented as $H_{\mathrm{e}} / L_{\mathrm{w}}$ or $M / V L_{\mathrm{w}}$ (where $H_{\mathrm{e}}$ is the effective wall height) rather than $H_{\mathrm{w}} / L_{\mathrm{w}}$. For the test setup used by Greifenhagen and Lestuzzi (2005) and Thomsen and Wallace (2004), the loading point was not at the top of the wall and the loading height is not included in Table 3.

In Table 3, the vertical reinforcement ratios reported for the two walls by Thomsen and Wallace (2004) are incorrect. The correct total vertical reinforcement ratios of RW1 and RW2 should be $1 \cdot 1 \%$, which is much higher than $0 \cdot 17 \%$ stated in Table 3 . The authors also incorrectly stated that, because of the low vertical reinforcement in these two specimens, flexure behaviour was dominated by a single crack at the base of the wall (Wibowo et al., 2013: p. 821). The observed test results reported by Thomsen and Wallace (2004) did not indicate a single flexural crack, and wall failure was controlled by buckling of the vertical reinforcement in the boundary elements.

It is unclear why the authors have elected to follow different procedures for the detailed and simplified models. For example, in the simplified model, behaviour is assumed to be dominated by either single or multiple flexural cracks based on whether $M_{\mathrm{cr}}>M_{\mathrm{u}}$ or $M_{\mathrm{cr}}<M_{\mathrm{u}}$, whereas for the detailed model, the authors did not differentiate these two modes of behaviour. The contributors agree with the two modes of behaviour proposed in the simplified model, but research by Henry (2013) suggests that even when $M_{\mathrm{cr}}<M_{\mathrm{u}}$, the equivalent plastic hinge length may be significantly less than $0.5 L_{\mathrm{w}}$ for lightly reinforced concrete walls. The use of a plastic hinge length of $0 \cdot 5 L_{\mathrm{w}}$ may explain why the ultimate drifts are not always well predicted by the proposed procedures. Furthermore, for the case of $M_{\mathrm{cr}}<M_{\mathrm{u}}$, the ultimate curvature in the simplified model was calculated assuming that concrete crushing and ultimate steel strain of $2.0 \%$ for ductile reinforcement ( $1 \cdot 0 \%$ for low ductile steel) occur simultaneously. In this case, the predicted drifts of walls with no end stirrups and walls with significant stirrups would be the same. This is unreasonable as, according to the authors' definition of lightly reinforced walls (total vertical reinforcement ratio of $0 \cdot 2-2 \cdot 0 \%$ ), compression failure in the wall ends is still possible and the ultimate drift would be dependent on the detailing and spacing of stirrups in the boundary elements. 


\section{Authors' response}

The authors are grateful for the comments made. The overall objective of the paper was to present an approximate model for estimating the load-drift behaviour of lightly reinforced rectangular structural walls for seismic design purposes using displacement-based methods. Designers typically have good understanding of the lateral force capacity of structural walls, but lesser understanding of and limited access to models to determine the corresponding drift behaviour. A comparison of the predicted and actual load-drift behaviour of the test walls provided in the paper is considered conservative and reasonable, but certainly not exact (see Figures 13-16). The points raised by the contributors are clarified as follows.

(a) Figure 1 shows a wide scatter of results, which reflects the wide typology of rectangular walls considered, particularly the level of detailing and quantity of reinforcement. Walls are further complicated in practice with different cross-section shapes and the effects of the interaction between the slab and wall, which were ignored in all the tests. The authors agree that the behaviour of a wall with $0 \cdot 2 \%$ reinforcement is different from a wall with $2.0 \%$ reinforcement in relation to the degree of cracking, stiffness and the tension stiffening effects (see Table 1).

(b) The definition of failure has historically been associated with a reduction in $20 \%$ of the peak lateral strength. However, from a collapse prevention perspective in regions of lower seismicity, an alternative definition is associated with the drift at which the gravity axial load can no longer be maintained. The failure drifts associated with these definitions are similar for walls and columns with high axial load ratios, but for lightly loaded elements typical of many structural walls, the drift at lateral load failure is considerably smaller than the drift at axial load failure (Wibowo et al., 2014).

(c) The authors agree that the term effective wall height is a better term to use rather than the wall height, particularly for different wall test loading configurations.

(d) The authors agree that the vertical reinforcement ratio in the Thomsen and Wallace (2004) tests was actually $1 \cdot 1 \%$. The value of $0 \cdot 17 \%$ quoted was for the internal section of the wall and did not include the boundary element reinforcement.

(e) The authors believe that a plastic hinge length of $0.5 L_{\mathrm{w}}$ is a reasonable representation of the plastic hinge length for design purposes, but acknowledge that there are many other models available, as listed in Table 2. The simplified wall model acknowledges that, for lightly reinforced walls, a single crack may form at the base and reduce the plastic hinge length to a function of the yield penetration length. This modification could be similarly extended to the more detailed wall model for lightly reinforced walls for cases where the cracking strength exceeds the ultimate moment strength.

$(f)$ The assumption of concrete crushing at $0.4 \%$ strain and the reinforcement steel extending to $2 \cdot 0 \%$ strain is considered a reasonable and conservative simplified modelling approach for estimating the ultimate curvature distribution for lightly reinforced structural walls for design purposes. Clearly this assumption is conservative for boundary elements that have confined concrete, where the compressive strains could be larger, but such well-detailed ductile structural walls were beyond the scope of the paper.

\section{REFERENCES}

Gebreyohaness A, Clifton C and Butterworth J (2011) Behaviour of inadequately detailed reinforced concrete walls. Proceedings of Australian Earthquake Engineering Society 2011 Conference, Barossa Valley, SA, Australia, Paper No. 23.

Greifenhagen C and Lestuzzi P (2005) Static cyclic tests on lightly reinforced concrete shear walls. Engineering Structures 27(11): 1703-1712.

Henry RS (2013) Assessment of minimum vertical reinforcement limits for RC walls. Bulletin of the New Zealand Society for Earthquake Engineering 46(2): 88-96.

Park R (1989) Evaluation of ductility of structures and structural assemblages from laboratory testing. Bulletin of the New Zealand National Society for Earthquake Engineering 22(3): 155-166.

Thomsen JH and Wallace JW (2004) Displacement based design of slender reinforced concrete structural walls - experimental verification. Journal of Structural Engineering 130(4): 618630.

Wibowo A, Wilson JL, Lam NTK and Gad EF (2013) Seismic performance of lightly reinforced structural walls for design purposes. Magazine of Concrete Research 65(13): 809-828, http://dx.doi.org/10.1680/macr.13.00021.

Wibowo A, Wilson JL, Lam NTKL and Gad EF (2014) Drift performance of lightly reinforced concrete columns. Journal of Engineering Structures 59(February): 522-535. 